\title{
Editorial
}

\section{Environmental Photocatalysis 2013}

\author{
Jiaguo Yu, ${ }^{1}$ Christos Trapalis, ${ }^{2}$ Pengyi Zhang, ${ }^{3}$ Guisheng Li, ${ }^{4}$ and Huogen $\mathrm{Yu}^{5}$ \\ ${ }^{1}$ State Key Laboratory of Advanced Technology for Material Synthesis and Processing, Wuhan University of Technology, \\ Luoshi Road No. 122, Wuhan 430070, China \\ ${ }^{2}$ Institute of Materials Science, National Centre for Scientific Research "Demokritos," Ag. Paraskevi, Attikis, Greece \\ ${ }^{3}$ State Key Joint Laboratory of Environment Simulation and Pollution Control, School of Environment, Tsinghua University, \\ Beijing, China \\ ${ }^{4}$ Department of Chemistry, Key Laboratory of Resource Chemistry of Ministry of Education, Shanghai Normal University, \\ Shanghai 200234, China \\ ${ }^{5}$ Department of Chemistry, School of Science, Wuhan University of Technology, Wuhan 430070, China
}

Correspondence should be addressed to Jiaguo Yu; jiaguoyu@yahoo.com

Received 16 December 2013; Accepted 16 December 2013

Copyright (C) 2013 Jiaguo Yu et al. This is an open access article distributed under the Creative Commons Attribution License, which permits unrestricted use, distribution, and reproduction in any medium, provided the original work is properly cited.

Semiconductor photocatalysis has caused enormous attention in recent year and has been demonstrated to be one of the "green" and effective methods for water and air purification, water disinfection, hazardous waste remediation, antibacterial, and self-cleaning. However, owing to low photocatalytic efficiency, the environmental applications of various photocatalytic materials and technologies are still very limited. Thus, more improvement and investigations are highly required from the viewpoint of practical use.

This special issue contains 20 papers, which are mainly related to pollutant degradation and environmental purification. Among them, 10 papers are related to composite of two semiconductors including $\mathrm{TiO}_{2}$ and other semiconductors, 4 papers deal with fabrication of new photocatalytic materials, 2 papers are about doping of $\mathrm{TiO}_{2}$, and 4 papers are devoted to immobilization of $\mathrm{TiO}_{2}$. Furthermore, there are 13 papers devoting degradation of pollutant in water, 4 papers on air purification including decomposition of formaldehyde, NO and benzene, 2 papers related to hydrogen production, and 1 paper dealing with bactericidal activity of $\mathrm{TiO}_{2}$. We would like to express our sincere thanks to all the authors for submitting their interesting works to this special issue. A brief summary of all 20 accepted papers is provided as follows.

In "A cost-effective solid-state approach to synthesize g- $\mathrm{C}_{3} \mathrm{~N}_{4}$ coated $\mathrm{TiO}_{2}$ nanocomposites with enhanced visible light photocatalytic activity," the authors describe the fabrication and photocatalytic performance of g- $\mathrm{C}_{3} \mathrm{~N}_{4} / \mathrm{TiO}_{2}$ nanocomposites by a facile solid-state method using urea and commercial $\mathrm{TiO}_{2}$ as precursors. The prepared nanocomposites exhibited enhanced absorption and photocatalytic performance for degradation of aqueous $\mathrm{MB}$ in visible light region.

The paper "Synthesis and characterization of pyrochlore $\mathrm{Bi}_{2} \mathrm{Sn}_{2} \mathrm{O}_{7}$ doping with praseodymium by hydrothermal method and its photocatalytic activity study" reports preparation of $\mathrm{Pr}$-doped $\mathrm{Bi}_{2} \mathrm{Sn}_{2} \mathrm{O}_{7}$ (BSO) by a hydrothermal method. The photocatalytic activity of the prepared samples was evaluated by the degradation of rhodamine Bextra (RhB) and 2,4-dichlorophenol (2,4-DCP) in aqueous solution under visible light. Pr-doped BSO samples exhibited enhanced visible-light photocatalytic activity and the optimal dopant amount of Pr was determined to be $1.0 \mathrm{~mol} \%$.

The paper "Single step formation of $\mathrm{C}-\mathrm{TiO}_{2}$ nanotubes: influence of applied voltage and their photocatalytic activity under solar illumination" presents fabrication of self-aligned and high-uniformity carbon $(\mathrm{C})$-titania $\left(\mathrm{TiO}_{2}\right)$ nanotube arrays by single step anodization of titanium (Ti) foil at $30 \mathrm{~V}$ for $1 \mathrm{~h}$. The photocatalytic activity evaluation of C$\mathrm{TiO}_{2}$ samples was performed by degradation of methyl orange (MO) solution. The results revealed that controlled nanoarchitecture $\mathrm{C}-\mathrm{TiO}_{2}$ photocatalyst led to a significant enhancement in photocatalytic activity. 
The paper "Removal of formaldehyde using highly active $\mathrm{Pt} / \mathrm{TiO}_{2}$ catalysts without irradiation" describes preparation of $\mathrm{TiO}_{2}$ supported $\mathrm{Pt}$ catalysts by sol-gel method and their application for eliminating formaldehyde $(\mathrm{HCHO})$ at room temperature without irradiation. More than $96 \%$ of the conversion of $\mathrm{HCHO}$ was obtained over $0.5 \mathrm{wt} \% \mathrm{Pt} / \mathrm{TiO}_{2}-\mathrm{H}_{2}$ sample, on which highly dispersed metallic Pt nanoparticles with $\sim 2$ nm were identified.

The paper "CTAB-assisted hydrothermal synthesis of $\mathrm{Bi}_{2} \mathrm{Sn}_{2} \mathrm{O}_{7}$ photocatalyst and its highly efficient degradation of organic dye under visible-light irradiation" reported preparation of Pyrochlore-type $\mathrm{Bi}_{2} \mathrm{Sn}_{2} \mathrm{O}_{7}$ (BSO) nanoparticles by a hydrothermal method assisted with cetyltrimethylammonium bromide (CTAB). The photocatalytic activity of the $\mathrm{BSO}$ assisted with $\mathrm{CTAB}$ was two times that of the reference BSO.

The paper " $\mathrm{H}_{2}$ fuels from photocatalytic splitting of seawater affected by nano- $\mathrm{TiO}_{2}$ promoted with $\mathrm{CuO}$ and $\mathrm{NiO}$ " described preparation and photocatalytic performance of nanostructured $\mathrm{TiO}_{2}$ loaded with $\mathrm{NiO}(2.5 \%)$ and $\mathrm{CuO}$ (2.5\%). The accumulated $\mathrm{H}_{2}$ yielded from the photocatalytic splitting of seawater containing oxalic acid $(50 \mathrm{mM})$ as the sacrificial reagents on $\mathrm{CuO} / \mathrm{nano}-\mathrm{TiO}_{2}$ was $8.53 \mu \mathrm{mol} / \mathrm{g}_{\text {cat }}$ after the $5 \mathrm{~h}$ radiation. On the $\mathrm{NiO} /$ nano- $-\mathrm{TiO}_{2}$ photocatalyst, the $\mathrm{H}_{2}$ yield was relatively low (i.e., $1.46 \mu \mathrm{mol} / \mathrm{g}_{\text {cat }}$ ).

In "Dynamic hydrogen production from methanol/water photo-splitting using Core@Shell-structured CuS@ $\mathrm{TiO}_{2}$ catalyst wrapped by high concentrated $\mathrm{TiO}_{2}$ particles," core@shell-structured CuS@ $\mathrm{TiO}_{2}$ catalysts were prepared and the prepared samples exhibited a wide absorption range above $700 \mathrm{~nm}$ comparing with pure $\mathrm{TiO}_{2}$. Hydrogen evolution rate from methanol/water photo-splitting over the core@shell-structured CuS@TiO, photocatalyst was about 10 -fold higher than pure CuS.

In "Enhanced visible light photocatalytic activity for $\mathrm{TiO}_{2}$ nanotube array films by codoping with tungsten and nitrogen," a series of $\mathrm{W}, \mathrm{N}$ codoped $\mathrm{TiO}_{2}$ nanotube arrays (TNAs) with different dopant contents, were fabricated by anodizing, followed with hydrothermal treatment. W and $\mathrm{N}$ codoping successfully extended the absorption of TNAs into the whole visible light region and resulted in remarkably enhanced photocatalytic activity under visible light irradiation.

The paper "Kinetics study of photocatalytic activity of flame-made unloaded and $\mathrm{Fe}$-loaded $\mathrm{CeO}_{2}$ nanoparticles" reported preparation and enhanced photocatalytic activity of Fe-doped and undoped $\mathrm{CeO}_{2}$ by flame spray pyrolysis method. Photocatalytic studies showed that $\mathrm{Fe}$-doped $\mathrm{CeO}_{2}$ sample exhibited higher activity than un-doped $\mathrm{CeO}_{2}$ sample, with optimal $2.00 \mathrm{~mol} \%$ of iron loading concentration.

The paper "Solar photocatalytic degradation of bisphenol A on immobilized $\mathrm{ZnO}$ or $\mathrm{TiO}_{2}$ " reported the removal of bisphenol A (BPA) under simulated solar irradiation in the presence of either $\mathrm{TiO}_{2}$ or $\mathrm{ZnO}$ catalysts immobilized onto glass plates. BPA degradation followed first-order reaction kinetics.

In "Supported zinc oxide photocatalyst for decolorization and mineralization of orange G dye wastewater under UV365 irradiation," a photocatalytic system by utilizing both cold cathode fluorescent light (CCFL) UV irradiation and steel mesh supported $\mathrm{ZnO}$ nanoparticles in a closed reactor for the degradation of azo dye C.I. Orange $\mathrm{G}(\mathrm{OG})$ was reported. The $\mathrm{ZnO}$-coated steel mesh can be repeatedly used over 10 cycles without significant loss of catalyst mass.

In "The multiple effects of precursors on the properties of polymeric carbon nitride," polymeric graphitic carbon nitride $\left(\mathrm{g}-\mathrm{C}_{3} \mathrm{~N}_{4}\right)$ materials were prepared by direct pyrolysis of thiourea, dicyandiamide, melamine, and urea under the same conditions, respectively. The photocatalytic activity of the samples was evaluated by the removal of $\mathrm{NO}$ in gas phase under visible light irradiation. Considering the cost, toxicity, and yield of the precursors and the properties of $\mathrm{g}-\mathrm{C}_{3} \mathrm{~N}_{4}$, the best precursor for preparation of $g-\mathrm{C}_{3} \mathrm{~N}_{4}$ was melamine.

In "One-step synthesis of $\mathrm{TiO}_{2}$ /perlite composites by flame spray pyrolysis and their photocatalytic behavior," $\mathrm{TiO}_{2}$ /perlite composites were prepared by facile one-step flame spray pyrolysis (FSP) route using titanium alkoxide (TIPO) and expanded perlite as Ti source and substrate, respectively. The porosity and the light absorbance of the $\mathrm{TiO}_{2}$ /perlite composites were examined and their photocatalytic activity in NO oxidation was evaluated. The best photocatalytic activity of the composites was connected to almost equal anatase-rutile ratio and possible synergetic effect of the two $\mathrm{TiO}_{2}$ phases.

The paper " $\mathrm{Au} / \mathrm{TiO}_{2}$ reusable photocatalysts for dye degradation" reported preparation of Nanogold-doped $\mathrm{TiO}_{2}$ catalysts and their application in the photodegradation of dye pollutants. Au-doped systems showed very good photoactivity in the degradation of dye pollutants under UV irradiation as well as in sunlight.

The paper "Fabrication, modification, and emerging applications of $\mathrm{TiO}_{2}$ nanotube arrays (TNAs) by electrochemical synthesis: a review" reviewed the recent progress of the new research achievements of TNAs on the preparation processes, forming mechanism, and modification. In addition, the authors also reviewed potential and significant applications in the photocatalytic degradation of pollutants, solar cells, water splitting, and other aspects. Finally, the existing problems and further prospects of this renascent and rapidly developing field were also briefly addressed and discussed.

In "Photocatalytic degradation of organic dyes by $\mathrm{H}_{4} \mathrm{SiW}_{6} \mathrm{Mo}_{6} \mathrm{O}_{40} / \mathrm{SiO}_{2}$ sensitized by $\mathrm{H}_{2} \mathrm{O}_{2}, " \mathrm{H}_{4} \mathrm{SiW}_{6} \mathrm{Mo}_{6} \mathrm{O}_{40} /$ $\mathrm{SiO}_{2}$ was sensitized by $\mathrm{H}_{2} \mathrm{O}_{2}$ solution that significantly improved its catalytic activity under simulated natural light. The photodegradation of malachite green, methyl orange, methylene blue, and Rhodamine B were also tested, and the degradation rate of dyes reached $90 \%-98 \%$.

In "Enhancement of photocatalytic activity on $\mathrm{TiO}_{2}$ nitrogen-doped carbon nanotubes nanocomposites," $\mathrm{TiO}_{2}$ nitrogen-doped carbon nanotubes $\left(\mathrm{TiO}_{2}-\mathrm{CNx}\right)$ nanocomposites were successfully synthesized by a facile hydrothermal method. $\mathrm{TiO}_{2}-\mathrm{CNx}$ nanocomposites exhibited much higher photocatalytic activity than neat $\mathrm{TiO}_{2}$ and $\mathrm{TiO}_{2}-\mathrm{CNT}$ mechanical nanocomposites. The improved photodegradation performances were attributed to the suppressed recombination of electrons and holes caused by the effective transfer of photogenerated electrons from $\mathrm{TiO}_{2}$ to $\mathrm{CNx}$. 
In "Effect of different calcination temperatures on the structural and photocatalytic performance of $\mathrm{Bi}-\mathrm{TiO}_{2} / \mathrm{SBA}$ 15 ," the $\mathrm{Bi}-\mathrm{TiO}_{2} / \mathrm{SBA}-15$ composite was synthesized by an easy wet impregnation method. It was found that SBA-15 retained the ordered hexagonal mesostructure after incorporation of $\mathrm{TiO}_{2}$ and $\mathrm{Bi}$. The $\mathrm{Bi}-\mathrm{TiO}_{2} / \mathrm{SBA}-15$ composite exhibited higher photocatalytic activities than pure $\mathrm{TiO}_{2}$ and $\mathrm{Bi}_{2} \mathrm{O}_{3}$.

The paper "Photocatalytic oxidation of gaseous benzene under $185 \mathrm{~nm}$ UV irradiation" reported that benzene removal efficiency of Photocatalytic oxidation (PCO) with $254 \mathrm{~nm}$ UV irradiation (denoted as 254-PCO) was only $2.1 \%$, while it was greatly increased to $51.5 \%$ in 185-PCO. 185-PCO exhibited superior capacity for benzene oxidation. In the 185-PCO process, much ozone was left in case of $\mathrm{TiO}_{2}$ as photocatalysts while it could be nearly eliminated by $1 \% \mathrm{Co}-\mathrm{TiO}_{2}$.

The paper "Bactericidal activity of $\mathrm{TiO}_{2}$ on cells of pseudomonas aeruginosa ATCC 27853" presented the antibacterial effects of $\mathrm{TiO}_{2}$ and light exposure (at $365 \mathrm{~nm}$ ) on Pseudomonas aeruginosa ATCC 27853. Following 90 minutes exposure to $\mathrm{TiO}_{2}$ and UV light, logarithm of cell density was reduced from 6 to 3 .

Jiaguo Yu

Christos Trapalis Pengyi Zhang Guisheng Li Huogen $\mathrm{Yu}$ 

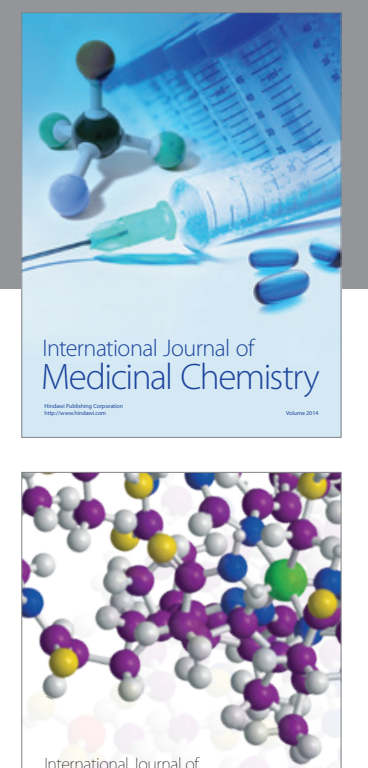

\section{Carbohydrate} Chemistry

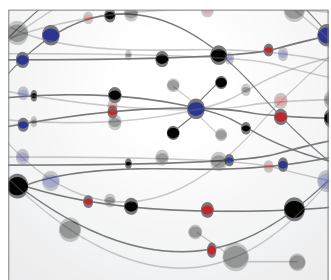

The Scientific World Journal
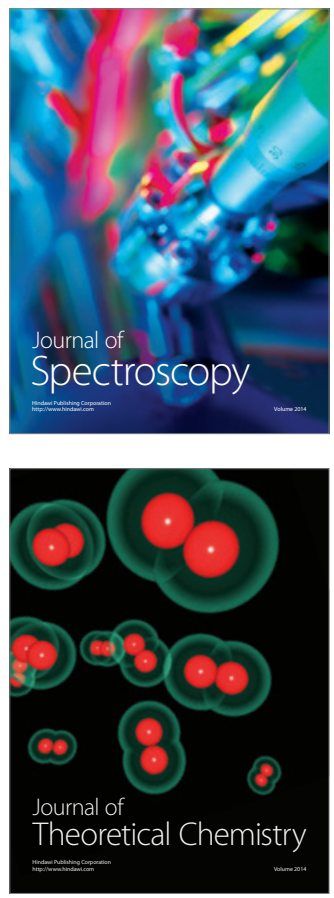
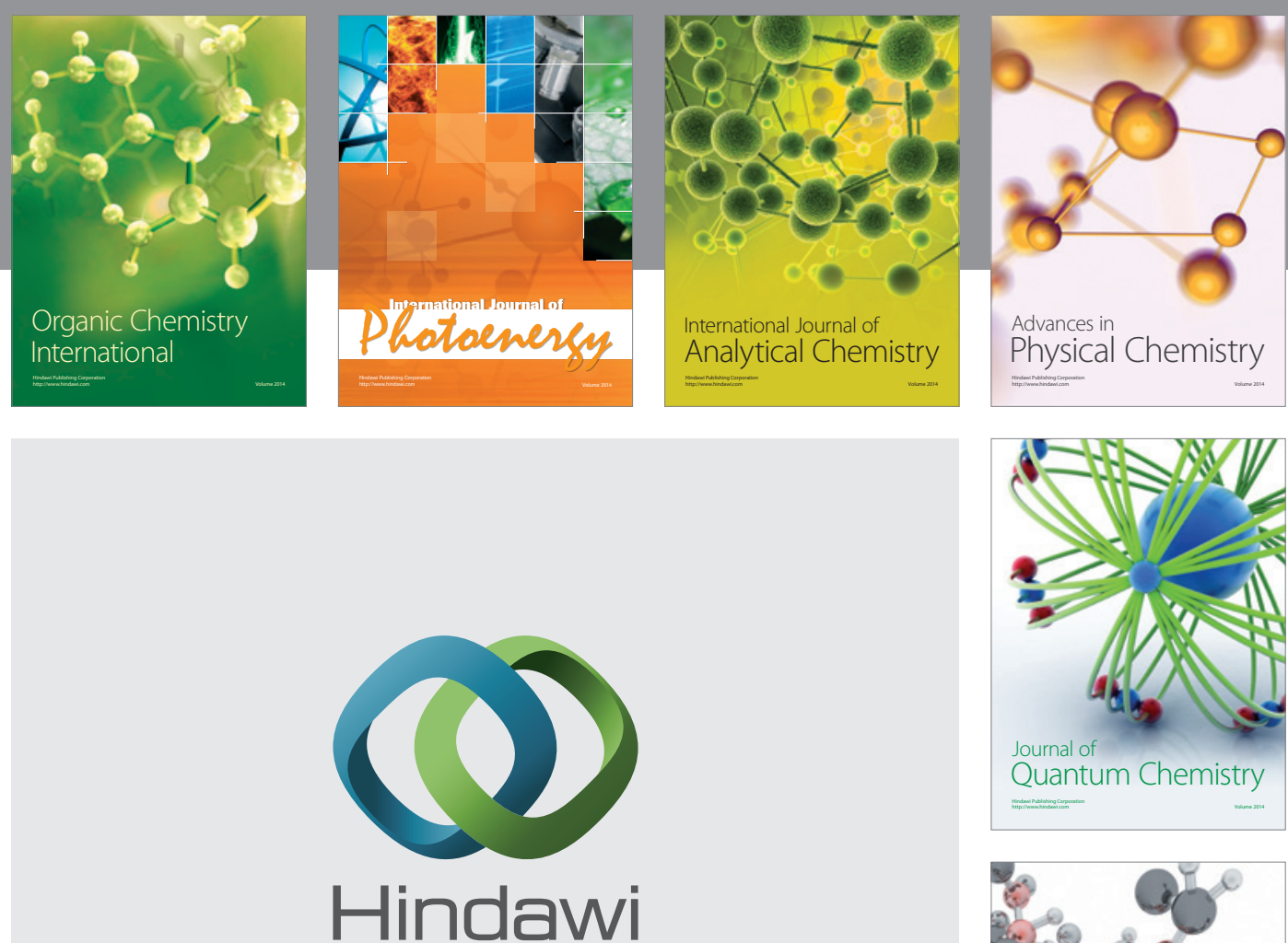

Submit your manuscripts at

http://www.hindawi.com

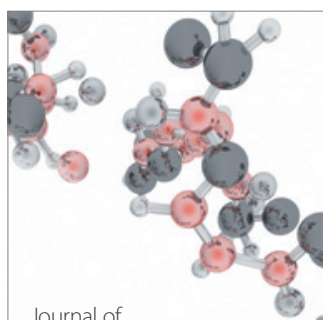

Analytical Methods

in Chemistry

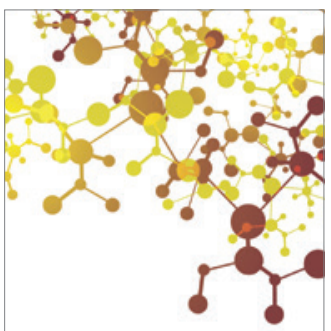

Journal of

Applied Chemistry

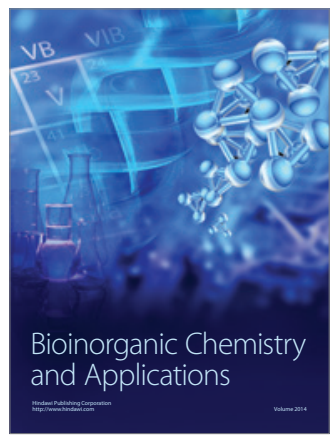

Inorganic Chemistry
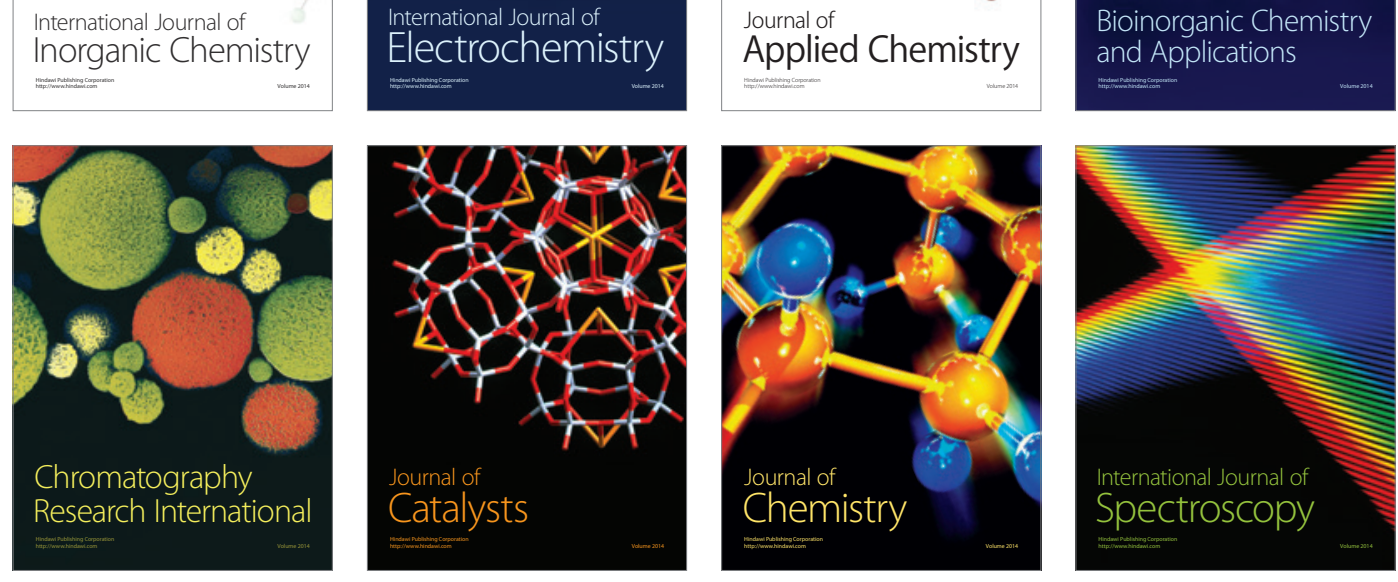